\title{
Impact of big data analytics in reverse supply chain of Indian manufacturing industries: An em- pirical research
}

\author{
Ajay Kumar Behera ${ }^{a^{*}}$
}

${ }^{a}$ S Iter, Soa Deemed to be University, Bhubaneswar, India

\section{CHRON I CLE A B T T A C T}

Article history:

Received: September 2, 2018

Received in revised format: October 20, 2018

Accepted: November 3, 2018

Available online:

November 3, 2018

Keywords:

Reverse supply chain levels

(RSCL)

Big data analytics (BDA)

Manufacturing industries

Reverse supply chain competences

\begin{abstract}
The main purpose of this paper is to know about the recent status of big data analytics (BDA) on various manufacturing and reverse supply chain levels (RSCL) in Indian industries. In particular, it emphasizes on understanding of BDA concept in Indian industries and proposes a structure to examine industries' development in executing BDA extends in reverse supply chain management (RSCM). A survey was conducted through questionnaires on RSCM levels of 500 industries. Of the 500 surveys that were mailed, 125 completed surveys were returned, corresponding to a response rate of 25 percent, which was slightly greater than previous studies. The information of Indian industries with respect to $\mathrm{BDA}$, the hurdles with boundaries to BDA-venture reception, and the connection with reverse supply chain levels and BDA learning were recognized. A structure was presented for the selection of BDA ventures in RSCM. This paper gives bits of knowledge to professionals to create activities including big data and RSCM, and presents utilitarian and predictable direction through the BDA-RSCM triangle structure as an extra device in the execution of BDA ventures in the RSCM factors. This paper does not provide outside legitimacy owing to limitations for the speculation of the outcomes even in the Indian surroundings, which originates from the present test. Future research ought to enhance the understanding in this area and spotlight on the effect of big data on reverse supply chains in developed countries.
\end{abstract}

\section{Introduction}

Big data analytics (BDA) has explored as a technique to achieve healthy advantage for manufacturing industries in current scenario (Tan et al., 2015; Davenport, 2006). It has reflected more importance to research scholars and academicians (Dubey et al., 2016). According to Strawn (2012), big data has great impact to industry 4.0 paradigm. Gobble (2013) considered BDA techniques as big innovation for remodeling in manufacturing industries. Currently, reverse supply chain management has received more attention by BDA (Jin et al., 2015; Hazen et al., 2014, 2016; Fosso Wamba et al., 2017; Gunasekaran et al., 2017; Pauleen \& Wang, 2017; Rothberg \& Erickson, 2017). Data, process, and management challenges are three classifications of big data as per (Sivarajah et al., 2017). With the help of resourcebased view (RBV) approach (Gunasekaran et al. 2017), it showed the importance and impact of resources and capabilities in supply chain costs and efficiency. RBV approach and model proposal were studied by Fosso Wamba et al. (2017) to have the impact of big data analytics capability (BDAC) on

* Corresponding author.

E-mail address: mail2ajaybehera@yahoo.co.in (A.K. Behera) 
industry performance. Industry performance and resources by BDAC are studied by Akhtar et al. (2016) and Gupta and George (2016), respectively. Though a lot of achievements are reflected in recent research papers, various gaps are remained open and particularly in empirical research (Comuzzi \& Patel, 2016; Strawn, 2012, Fosso Wamba et al., 2015; Kache \& Seuring, 2017). BDAC on industry performance and sustainable manufacturing were supported by different researchers (e.g. Fosso Wamba et al., 2017; Gupta \& George, 2016, Dubey et al., 2016). However, a lot of gaps exist in reverse supply chain regarding BDA projects on development of frameworks and empirical research particularly in developing countries. Manufacturing industries do not know about the development level of BDA or whether the industries' present abilities are adequate for directing an execution of a BDA venture in RSCM. The research on BDA is not sufficiently wide and does not offer models as well as structures to examine the attainability of actualizing a big data venture. In this unique situation, Indian writings about BDA in reverse supply chain management (RSCM) can be comprehended to be moderately restricted. To add to the progression of information and decrease perception flaws related with BDA in RSCM, this examination means to answer the accompanying inquiries:

Question 1: What are the troubles with boundaries for the reception of BDA in Indian reverse supply chains?

Question 2: What are the fundamental contrasts and effects of BDA on various manufacturing industries and reverse supply chain levels?

The essential commitment of the present paper is the distinguishing proof of the fundamental troubles and boundaries for execution of BDA techniques in RSCM conditions in Indian manufacturing industries. The second commitment is the proposition of a reference framework (BDA-RSCM triangle) to help researchers in BDA projects with regards to RSCM. Besides, this paper adds to the BDAC reverse supply chain literature (Akter et al., 2016; Fosso Wamba et al., 2017; Gupta \& George, 2016) by researching segments of reverse supply chain partnerships (RSCP), human knowledge (HK), and innovation culture (IC) (BDA-RSCM triangle).

\section{Literature Review}

\subsection{Big Data Analytics}

Cox and Ellsworth (1997) suggested 'Big Data' as the first term and found that data are very large to store in the computer. This type of problem is called as Big Data. Chen et al. $(2013,2004)$ developed business intelligence and analytics (BI\&A) framework in connection to Big Data. Data mining and statistical analysis are described by the application of (BI\&A) technique (Chen et al., 2012). Recently industries face challenges to collect and store huge data in order to retrieve useful result (Bakshi, 2012). So industries should realize the importance of BDA regarding secured data and business advantage (Gobble, 2013; McAfee \& Brynjolfsson, 2012). Reverse smart supply chain approach can be enhanced by Big Data Analytics in connection to industry 4.0 paradigms. Sensor data and data rise are achieved by Internet of Things (IoT) (Gobble, 2013 \& Zhou et al., 2014). BDA is an important technique for gaining competitive advantage although other techniques in reverse supply chain are used to generate data.

\subsection{Developments in $B D A$}

BDA has lot of contribution to RSCM (Giannakis \& Louis, 2016; Zhao et al., 2017; Schoenherr \& Speier-Pero, 2015). However, the keyword BDA is not available to all decision makers worldwide. Nevertheless, it derived from the 3V approach (volume, velocity, and variety) (Watson, 2014) and $5 \mathrm{~V}$ concepts (volume, velocity, variety, veracity, and value) (Jin et al., 2015; Kune et al., 2016; Fosso Wamba et al., 2017). Table 1 shows a sample of the data generated ( unit time period) by different manufacturing industries in 2017 by taking complexity into consideration. 
Table 1

Data generated in unit time period in 2017

\begin{tabular}{ccc}
\hline organization & source & data \\
\hline ola & passengers & 1,389 \\
uber & passengers & 1,389 \\
YouTube & Video display & $2,682,000$ \\
WhatsApp & Writings & $20,700,000$ \\
Facebook & Users & 216,302 photos \\
LinkedIn & Number of accounts & 120 \\
Emails & Sent messages & $150,000,000$ \\
Google & Content views & $68,500,000$ words \\
Twitter & tweets & 347,222 \\
\hline Instagram & Like users & $2,430,555$ posts \\
\hline
\end{tabular}

\subsection{BDA being latest tool for Reverse Supply Chain}

A lot of papers have been published regarding big data after Davenport's publication (Davenport, 2006). Due to recent advancements in computations, the term analytics has been converted to BDA which is beneficial to industries and practitioners. The terms innovation, competition, and productivity are addressed by Manyika et al. (2011) and found that BDA has great impact on market framework. BDA is responsible for predictive analytics and data science in order to transform reverse supply chain. Big problems can be solved and innovation opportunities are found with the help of BDA (Marshall et al., 2015). Operational and strategic level are handled by BDA as it has great impact on industries. Richey Jr et al. (2016) investigated ten critical success factors (CSF).

\subsection{Conceptual structure for BDA-RSCM}

Structures are needful perspectives to BDA (Chae, 2015; Addo-Tenkorang \& Helo, 2016; Kache \& Seuring, 2017). The framework of this research is retrieved from new developments in the BDAC theory (Akter et al., 2016; Gupta \& George, 2016; Fosso Wamba et al., 2017). Various constructs were located after a lot of reviews of BDA and BDAC. Due to conjoint analysis of corresponding interactions, BDA-RSCM triangle can be better explained.



Fig. 1. BDA-RSCM Triangle 
The elements of BDA-RSCM triangle are nearer to the segmentation of Big Data availability (Gupta and George, 2016). The proposed structure is shown in Fig. 1. The current structure has three vital elements: (a) RSCP, (b) HK, and (c) IC. Sustainability is an important criteria for any industry by using BDA. The BDA-RSCM triangle explains about human knowledge, innovation culture and RSCP. Human knowledge explains about monitoring the BDA projects, Innovation culture reflects about the maturity level of industry and RSCP manages all about reverse supply chain data flow. It is obvious that the BDA-RSCM triangle is assumed as the introductory technique for industries to initiate a BDA-RSCM project. To acquire positive results and successful on BDA projects, it is vital to execute above three elements.

1-Reverse supply chain partnership, 2- Human Knowledge, 3-Innovation culture

4- RSCP - HK interaction, 5- IC-SCP interaction, 6-BDA-RSCM critical triangle

7- HK-IC interaction

\section{Research Methodology}

A survey-method is conducted in this study. It is vastly related to reverse supply chain analysis (Aggestam, et al., 2017; Gunasekaran et al., 2017; Dubey et al., 2016; Schoenherr et al., 2015; Larson, 2005). By using a 1-7 Likert scale, the importance of each element (RSCP, HK, IC) was measured which ranged from strongly disagree (1) to strongly agree (7) (Papadopoulos et al., 2017).

\subsection{Data collection}

125 replies are collected from 500 surveys that were sent by using various social network sites, with a 25 percent response rate, which was satisfactory compared to previous reverse supply chain studies (George \& Gupta, 2016; Dubey et al., 2016). Units having less than 50 employees had response of 16\%, less than 100 employees had $32 \%$, and more than 200 employees were the major respondents from the sample. The potential respondents are Chief Executive officers (10\%), Executives (15\%), Chief Executives (10\%), Junior managers (20\%), and analysts (45\%). A questionnaire was developed using the total design method (Gunasekaran et al., 2017). Different items were collected from earlier published studies. The questionnaire at the initial stage was sent to selected persons for pretesting. questionnaire was sent to selected person after Pilot test. Modifications were made wherever necessary and unreliable items were eliminated (Zelbst et al., 2012; Gunasekaran et al., 2017). Then, the final version of the questionnaire was designed. A database was created by selecting all leading manufacturing industries. The sample firms defined in the database are randomly selected. multiple regression analysis was performed. Reliability test was done having Cronbach's alpha exceeded 0.70 (Fosso Wamba et al., 2017; Gunasekaran et al., 2017).

\section{Data and Result Analysis}

\subsection{Descriptive statistics}

The response rate was 25\% and Likert scale of 7- point was used (Gunasekaran et al., 2017; Chen \& Paulraj, 2004). The value of Cronbach's alpha was 0.71 after the reliability test of data (Landis \& Koch, 1977). Table 2 reflects the response rate by different industries. One third of the response rate was achieved by Aluminum industries followed by copper, automotive and steel industries with $16.0 \%, 8.8 \%$, and $8.0 \%$, respectively. The other industries such as Oil and Gas, Heavy Industries, Machines and Equipment, Food/Beverage and Plastics achieved $4.8 \%$ of the response rate. The leather company, the conventional Indian industry, achieved $4.0 \%$.Wood, computer and electronics, textiles have achieved $2.4 \%$. 
Table 2

Response rate by manufacturing industries

\begin{tabular}{lcc}
\hline Industries & $\mathrm{N}$ & $\%$ \\
\hline Aluminium & 40 & 32.0 \\
Copper & 20 & 16.0 \\
Automotive & 11 & 8.8 \\
Steel Industry & 10 & 8.0 \\
Oil and Gas & 6 & 4.8 \\
Heavy Industries & 6 & 4.8 \\
Machines and Equipment & 6 & 4.8 \\
Food/Beverage & 6 & 4.8 \\
Plastics & 6 & 4.8 \\
Leather & 5 & 4.0 \\
Wood & 3 & 2.4 \\
Computer and Electronics & 3 & 2.4 \\
Textiles & 3 & 2.4 \\
Total & 125 & 100 \\
\hline
\end{tabular}

Table 3

Response rate by industry size

\begin{tabular}{lcc}
\hline \multicolumn{1}{c}{ Size of industry(employee wise) } & $\mathrm{N}$ & $\%$ \\
\hline Less than 50 & 20 & 16.0 \\
Less than 100 & 40 & 32.0 \\
Less than 500 & 5 & 4.0 \\
Less than 1000 & 5 & 4.0 \\
$\geq 1000$ & 55 & 44.0 \\
Total & $\mathbf{1 2 5}$ & $\mathbf{1 0 0}$ \\
\hline
\end{tabular}

Table 3 lists the industry sizes and Table- 4 shows respondents' profession.

Table 4

Response rate by Profession

\begin{tabular}{|c|c|c|}
\hline Profession & $\mathrm{N}$ & $\%$ \\
\hline Reverse Supply chain Analyst & 50 & 40.0 \\
\hline Intra trade analyst & 10 & 8.0 \\
\hline Data Analyst & 5 & 4.0 \\
\hline Chief Executive officers & 15 & 12.0 \\
\hline Executives & 5 & 4.0 \\
\hline Chief Executives & 20 & 16.0 \\
\hline Junior managers & 20 & 16.0 \\
\hline Total & 125 & 100 \\
\hline
\end{tabular}

Reverse Supply chain Analyst, Intra trade analyst and Data Analyst represent more than 50\% of the respondents. It is evident that there is a positive correlation with the aluminum industries. The respondents like CEOs participations were very lucrative as compared to other respondents. The mean average of professionals having BDA knowledge is 3.58, but it is observed that there is a huge gap when BDA utilization in reverse supply chain. The circumstance deteriorates when BDA ventures are accounted for the short time period. The principle hindrances in the utilization of BDA in RSCM ventures are principally connected with the absence of affirmation of the advantages of utilizing BDA and access and expenses related with capital speculations. Different boundaries that have been accounted for are the absence of capable experts in associations and a business opportunity for the advancement of BDA ventures. These outcomes can be translated as per the grouping of RSCM (Gupta \& George, 2016). Table 5 demonstrates the connection among Profession and BDA knowledge. It may be noticed that there is a relation between BDA knowledge and reverse supply chain levels. In this way, Executives and Chief Executive officers have more BDA knowledge than other practitioners. Then again, Junior managers achieved just the fourth rank. 
Table 5

Profession versus BDA knowledge

\begin{tabular}{lccc}
\hline Profession & Mean & $\mathrm{N}$ & Standard Deviation \\
\hline Chief Executives & 4.5652 & 20 & 0.50687 \\
VP Executives & 4.0000 & 5 & 0.00000 \\
Chief Executive officers & 3.5625 & 15 & 0.51235 \\
Junior managers & 3.5455 & 20 & 0.50876 \\
Reverse Supply chain analyst & 3.5222 & 50 & 1.04517 \\
Intra trade analyst & 2.9999 & 10 & 0.00000 \\
Data Analyst & 2.9999 & 5 & 0.00000 \\
Total & $\mathbf{3 . 5 8 3 6}$ & $\mathbf{1 2 5}$ & $\mathbf{0 . 8 9 5 1 3}$ \\
\hline
\end{tabular}

What's more, it is imperative to look at BDA knowledge in various industries. Table 6 analyzes industries and their BDA knowledge. Copper, Food/Beverage, and Steel Industry showed high BDA knowledge. Then again, the Wood and Leather industry has sound information about BDA.

Table 6

Industry versus BDA knowledge

\begin{tabular}{lccc}
\hline \multicolumn{1}{c}{ Industries } & Mean & $\mathrm{N}$ & Standard Deviation \\
\hline Aluminium & 4.0345 & 40 & 0.94426 \\
Copper & 4.0000 & 20 & 0.00001 \\
Automotive & 3.9999 & 11 & 0.64357 \\
Steel Industry & 3.9256 & 10 & 0.27759 \\
Oil and Gas & 3.9352 & 6 & 0.36585 \\
Heavy Industries & 3.8400 & 6 & 0.51000 \\
Machines and Equipment & 3.5401 & 6 & 0.93933 \\
Food/Beverage & 3.2747 & 6 & 0.74492 \\
Plastics & 3.1328 & 6 & 0.36695 \\
Leather & 2.9999 & 5 & 1.40420 \\
Wood & 2.9999 & 3 & 0.00001 \\
Computer and Electronics & 2.6400 & 3 & 1.24721 \\
Textiles & 2.0001 & 3 & 0.00001 \\
Total & $\mathbf{3 . 5 8 3 6}$ & 125 & $\mathbf{0 . 8 8 4 1 2}$ \\
\hline
\end{tabular}

\subsection{Skewness and Kurtosis}

This data used as skewness and kurtosis technique (Gunasekaran et al., 2017; Dubey et al., 2016; Curran et al., 1996). As detailed in Table 7, the most extreme total estimation of skewness was 0.753 and 1.540 for kurtosis. The numerical values are well inside for skewness $(<2)$ and kurtosis $(<7)($ Gunasekaran et al., 2017; Curran et al., 1996).

Table 7

Skewness and kurtosis analysis

\begin{tabular}{cccccc} 
& N & \multicolumn{2}{c}{ SKEWNESS } & \multicolumn{2}{c}{ KURTOSIS } \\
& STATISTIC & STATISTIC & STD. ERROR & STATISTIC & STD. ERROR \\
\hline BDA_PRO & 125 & 0.307 & 0.194 & -1.261 & 0.377 \\
BDA_RSCM & 125 & 0.705 & 0.194 & -0.688 & 0.377 \\
RSCM_INN & 125 & -0.131 & 0.194 & -1.525 & 0.377 \\
BDA_KNO & 125 & -0.752 & 0.194 & 1.072 & 0.377 \\
G_OTP & 125 & -0.211 & 0.194 & -1.345 & 0.377 \\
G_MTP & 125 & -0.275 & 0.194 & -0.913 & 0.377 \\
G_BDAB & 125 & -0.632 & 0.194 & 0.377 \\
H_INV & 125 & -0.288 & 0.194 & 0.377 \\
IT_ADP & 125 & 0.481 & 0.194 & -1.354 & 0.377 \\
IT_SEC & 125 & 0.375 & -1.541 & 0.377 \\
\hline BDA_PRO = ventures to use BDA in unit period; BDA_RSCM = BDA application in RSCM; RSCM_INN = R SCM innovation; BDA_KNO \\
= BDA knowledge; G_OTP = Gap of talented people in the industry; G_MTP = Gap of talented people in the market; G_BDAB = Gap of BDA
\end{tabular}




\subsection{Multiple regression analysis}

This research used various multiple regression analysis (Gunasekaran et al., 2017; Eckstein et al., 2015) to investigate the connections among dependent and independent variables. Our hypotheses to support the BDA-RSCM triangle are:

$\mathrm{H} 1 . \mathrm{HK} \rightarrow \mathrm{IC}-$ HK has significant positive effect on Reliability and represents a boundaries to BDA adoption in Reverse supply chains.

$\mathrm{H} 2 . \mathrm{RSCP} \rightarrow \mathrm{HK}$ - RSCP has significant positive effect on $H K$ and represent a hurdles to BDA adoption in reverse supply chains.

$\mathrm{H} 3$. IC $\rightarrow \mathrm{RSCP}-$ IC has significant positive effect on $R S C P$ and varies in organisational and reverse supply chain levels.

Regression analysis has been used to have the hypothesis testing. HK and IC are considered as independent variable and dependent variable in hypothesis-1 respectively (i.e. $\mathrm{HK} \rightarrow \mathrm{IC}$ ) where HK is positively related to innovation culture and represents a boundary to BDA adoption in reverse supply chains $(\beta=0.533 ; t=7.787 ; p=0.000)$. HK and RSCP are considered as independent variable and dependent variable respectively in hypothesis-2(i.e. RSCP $\rightarrow \mathrm{HK}$ ) where RSCPs are positively related to HK and represent a hurdle to BDA adoption in Indian reverse supply chains $(\beta=0.473 ; t=6.641 ; p=0.000)$. Similarly IC and RSCP are taken as independent and dependent variables in hypothesis-3(i.e. IC $\rightarrow$ RSCP).Hypothesis-3 stated that IC has significant positive effect on RSCP and varies in organizational and reverse supply chain levels. This hypothesis was supported as well $(\beta=0.470 ; t=6.578 ; p=0.000)$. The results support the critical triangle, suggesting model strength and recommending these structures as an initial tool for practitioners to analyze an industry capabilities regarding BDA venture.

\subsection{Correlation analysis}

Table 8 shows the Pearson correlation coefficients. The coefficients show the relations between various elements.

Table 8

Pearson's correlation coefficients

\begin{tabular}{|c|c|c|c|c|c|c|c|c|c|c|}
\hline & BDA_PRO & BDA_RSCM & RSCM_INN & BDA_KNO & G_OTP & G_MTP & G_BDAB & H_INV & IT_ADP & IT_SEC \\
\hline BDA_PRO & 1 & & & & & & & & & \\
\hline BDA_RSCM & 0.7187 & 1 & & & & & & & & \\
\hline RSCM_INN & 0.540 & 0.483 & 1 & & & & & & & \\
\hline BDA_KNO & 0.524 & 0.434 & 0.028 & 1 & & & & & & \\
\hline G_OTP & 0.365 & 0.147 & 0.031 & 0.340 & 1 & & & & & \\
\hline G_MTP & 0.651 & 0.380 & 0.234 & 0.493 & 0.754 & 1 & & & & \\
\hline G_BDAB & 0.482 & 0.095 & 0.432 & 0.061 & 0.425 & 0.695 & 1 & & & \\
\hline H_INV & 0.351 & 0.310 & $-0,036$ & 0.417 & 0.563 & 0.665 & 0.357 & 1 & & \\
\hline IT_ADP & 0.416 & 0.410 & 0.332 & -0.022 & 0.324 & 0.308 & 0.147 & 0.341 & 1 & \\
\hline IT_SEC & 0.395 & 0.293 & 0.413 & 0.131 & 0.264 & 0.511 & 0.344 & 0.631 & 0.470 & 1 \\
\hline
\end{tabular}

BDA_PRO $=$ ventures to use BDA in unit period; BDA_RSCM $=$ BDA application in RSCM; RSCM_INN = R SCM innovation; BDA_KNO = BDA knowledge; G_OTP = Gap of talented people in the industry; G_MTP = Gap of talented people in the market; G BDAB = Gap of BDA benefits; H INV = High investments; IT ADP = IT adaption; IT SEC $=$ IT security. 


\section{Discussion and Conclusions}

This paper reflects to an exact research in BDA in context to reverse supply chain of Indian manufacturing industries. It makes a profitable commitment to short out the gaps in empirical research including BDA in RSCM (Fosso Wamba et al., 2015). Since BDA can be utilized in companies which are irrespective of size (Addo-Tenkorang and Helo, 2016), it is important to comprehend the diverse ideal models as well as methodologies created. Moreover, this work outlines the ongoing progress achieved in studies with respect to BDA and BDAC. Besides, it portrays the upper hand that BDA can give to industries and the enthusiasm for $\mathrm{KM}$ with respect to this point. Till now, there have been no arguments that talk about BDA-RSCM ventures in developing regions. This topic gave brief direction to sort out this flaw. At last, our study based on survey added to develop a structure for BDA ventures. The BDA-RSCM triangle can be utilized as an initial methodology for industries to start BDA- RSCM projects. HK, IC, and RSCP are three basic elements of constructs. For industries to be fruitful in BDA reverse supply chain ventures, it is essential for them to have clear approaches actualized in these elements. This study offers the open door for professionals to discuss the commitment that BDA can make to their industries, particularly in the reverse supply chain. The proposed system can economically affect industries that execute BDA ventures as it features the need of a basic on asset usage and effective administration. This work gives experiences to reverse supply chain organizations and organizations that are occupied with executing BDA ventures. Additionally, BDA can be a basic way to deal with enhancing the level of reverse logistic services. Besides, attainment is required to deal with the BDA fundamentals (Fosso Wamba et al., 2017) and to accomplish better outcomes. The BDA-RSCM triangle has a few ramifications for experts. Apex administration requires a high level of attention to the advantages of BDA and the basic elements of human knowledge, innovation culture, and RSCM networks. As stated, the BDA-RSCM triangle ought to be utilized as an essential instrument for BDA ventures. In the event that all elements of the triangle are not fulfilled, a BDA project can't be executed. This paper has made a hypothetical and in addition pragmatic commitment. From the perspective of a professional, the basic triangle fills in as a structure for practitioners to analyze if the industry is prepared to execute a BDA venture. The BDA-RSCM triangle provides directions for researchers to test experimentally its strength in different countries.

This research has a few constraints. The first is that the examination was restricted to manufacturing industries in India. In light of the discoveries of this research, the learning of reverse supply chain organizations in BDA is beginning as the organizations are in the primary stage. Second, this study does not include service industries. Third, top executives should give suggestions to help industries. Future investigations utilizing the structure proposed by the BDA-RSCM triangle can be an opportunity for researchers to propel this theme. Different studies that expand this exploration field could be with respect to the effect of reverse supply chain network in developing countries. It is important to extend this subject with studies that give knowledge about the elements that accelerate the procedure with the end goal to fulfill the BDA-SCM triangle. At long last, a recommendation to the network of scientists and professionals is to recognize other key achievement factors in BDA-RSCM in developing nations. It may be profitable to execute the BDA-RSCM triangle structure in manufacturing industries and check whether there are contrasts with respect to BDA execution.

\section{References}

Addo-Tenkorang, R., \& Helo, P. T. (2016). Big data applications in operations/supply-chain management: A literature review. Computers \& Industrial Engineering, 101, 528-543.

Aggestam, V., Fleiß, E., \& Posch, A. (2017). Scaling-up short food supply chains? A survey study on the drivers behind the intention of food producers. Journal of rural studies, 51, 64-72.

Akhtar, P., Khan, Z., Rao-Nicholson, R., \& Zhang, M. (2016). Building relationship innovation in global collaborative partnerships: big data analytics and traditional organizational powers. $R \& D$ Management. 
Akter, S., Wamba, S. F., Gunasekaran, A., Dubey, R., \& Childe, S. J. (2016). How to improve firm performance using big data analytics capability and business strategy alignment?. International Journal of Production Economics, 182, 113-131.

Chae, B. K. (2015). Insights from hashtag\# supplychain and Twitter Analytics: Considering Twitter and Twitter data for supply chain practice and research. International Journal of Production Economics, 165, 247-259.

Chauhan, S., Agarwal, N., \& Kar, A. K. (2016). Addressing big data challenges in smart cities: a systematic literature review. info, 18(4), 73-90.

Chen, J., Chen, Y., Du, X., Li, C., Lu, J., Zhao, S., \& Zhou, X. (2013). Big data challenge: a data management perspective. Frontiers of Computer Science, 7(2), 157-164.

Chen, I. J., \& Paulraj, A. (2004). Towards a theory of supply chain management: the constructs and measurements. Journal of operations management, 22(2), 119-150.

Comuzzi, M., \& Patel, A. (2016). How organisations leverage big data: A maturity model. Industrial Management \& Data Systems, 116(8), 1468-1492.

Curran, P. J., West, S. G., \& Finch, J. F. (1996). The robustness of test statistics to nonnormality and specification error in confirmatory factor analysis. Psychological methods, 1(1), 16.

Davenport, T. Н. (2006). Competing on analytics. harvard business review, 84 (1), 98. Надійшла до редколегіï, 3, 14.

Dubey, R., Gunasekaran, A., Childe, S. J., Wamba, S. F., \& Papadopoulos, T. (2016). The impact of big data on world-class sustainable manufacturing. The International Journal of Advanced Manufacturing Technology, 84(1-4), 631-645.

Eckstein, D., Goellner, M., Blome, C., \& Henke, M. (2015). The performance impact of supply chain agility and supply chain adaptability: the moderating effect of product complexity. International Journal of Production Research, 53(10), 3028-3046.

Gunasekaran, A., Papadopoulos, T., Dubey, R., Wamba, S. F., Childe, S. J., Hazen, B., \& Akter, S. (2017). Big data and predictive analytics for supply chain and organizational performance. Journal of Business Research, 70, 308-317.

Gupta, M., \& George, J. F. (2016). Toward the development of a big data analytics capability. Information \& Management, 53(8), 1049-1064.

Hazen, B. T., Boone, C. A., Ezell, J. D., \& Jones-Farmer, L. A. (2014). Data quality for data science, predictive analytics, and big data in supply chain management: An introduction to the problem and suggestions for research and applications. International Journal of Production Economics, 154, $72-$ 80 .

Hazen, B. T., Skipper, J. B., Ezell, J. D., \& Boone, C. A. (2016). Big Data and predictive analytics for supply chain sustainability: A theory-driven research agenda. Computers \& Industrial Engineering, 101, 592-598.

He, W., Wang, F. K., \& Akula, V. (2017). Managing extracted knowledge from big social media data for business decision making. Journal of Knowledge Management, 21(2), 275-294.

Jin, X., Wah, B. W., Cheng, X., \& Wang, Y. (2015). Significance and challenges of big data research. Big Data Research, 2(2), 59-64.

Kache, F., \& Seuring, S. (2017). Challenges and opportunities of digital information at the intersection of Big Data Analytics and supply chain management. International Journal of Operations \& Production Management, 37(1), 10-36.

Kune, R., Konugurthi, P. K., Agarwal, A., Chillarige, R. R., \& Buyya, R. (2016). The anatomy of big data computing. Software: Practice and Experience, 46(1), 79-105.

Landis, J. R., \& Koch, G. G. (1977). The measurement of observer agreement for categorical data. biometrics, 159-174.

Larson, P. D. (2005). A note on mail surveys and response rates in logistics research. Journal of Business Logistics, 26(2), 211-222.

McAfee, A., Brynjolfsson, E., Davenport, T. H., Patil, D. J., \& Barton, D. (2012). Big data: the management revolution. Harvard business review, 90(10), 60-68. 
Manyika, J., Chui, M., Brown, B., Bughin, J., Dobbs, R., Roxburgh, C., \& Byers, A. H. (2011). Big data: The next frontier for innovation, competition, and productivity.

Marshall, A., Mueck, S., \& Shockley, R. (2015). How leading organizations use big data and analytics to innovate. Strategy \& Leadership, 43(5), 32-39.

Papadopoulos, T., Gunasekaran, A., Dubey, R., Altay, N., Childe, S. J., \& Fosso-Wamba, S. (2017). The role of Big Data in explaining disaster resilience in supply chains for sustainability. Journal of Cleaner Production, 142, 1108-1118.

Pauleen, D. J., \& Wang, W. Y. (2017). Does big data mean big knowledge? KM perspectives on big data and analytics. Journal of Knowledge Management, 21(1), 1-6.

Rothberg, H. N., \& Erickson, G. S. (2017). Big data systems: knowledge transfer or intelligence insights?. Journal of Knowledge Management, 21(1), 92-112.

Schoenherr, T., \& Speier-Pero, C. (2015). Data science, predictive analytics, and big data in supply chain management: Current state and future potential. Journal of Business Logistics, 36(1), 120-132.

Sivarajah, U., Kamal, M. M., Irani, Z., \& Weerakkody, V. (2017). Critical analysis of Big Data challenges and analytical methods. Journal of Business Research, 70, 263-286.

Strawn, G. O. (2012). Scientific Research: How Many Paradigms?. Educause Review, 47(3), 26.

Tan, K. H., Zhan, Y., Ji, G., Ye, F., \& Chang, C. (2015). Harvesting big data to enhance supply chain innovation capabilities: An analytic infrastructure based on deduction graph. International Journal of Production Economics, 165, 223-233.

Var, I. (1998). Multivariate data analysis. vectors, 8(2), 125-136.

Wang, G., Gunasekaran, A., Ngai, E. W., \& Papadopoulos, T. (2016). Big data analytics in logistics and supply chain management: Certain investigations for research and applications. International Journal of Production Economics, 176, 98-110.

Wamba, S. F., Akter, S., Edwards, A., Chopin, G., \& Gnanzou, D. (2015). How 'big data'can make big impact: Findings from a systematic review and a longitudinal case study. International Journal of Production Economics, 165, 234-246.

Wamba, S. F., Gunasekaran, A., Akter, S., Ren, S. J. F., Dubey, R., \& Childe, S. J. (2017). Big data analytics and firm performance: Effects of dynamic capabilities. Journal of Business Research, 70 , 356-365.

Wang, S., Wan, J., Li, D., \& Zhang, C. (2016). Implementing smart factory of industrie 4.0: an outlook. International Journal of Distributed Sensor Networks, 12(1), 3159805.

Watson, H. J. (2014). Tutorial: Big data analytics: Concepts, technologies, and applications. CAIS, 34, 65.

Zelbst, P. J., Green, K. W., Sower, V. E., \& Reyes, P. M. (2012). Impact of RFID on manufacturing effectiveness and efficiency. International Journal of Operations \& Production Management, 32(3), 329-350.

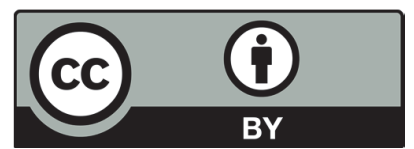

(C) 2018 by the authors; licensee Growing Science, Canada. This is an open access article distributed under the terms and conditions of the Creative Commons Attribution (CCBY) license (http://creativecommons.org/licenses/by/4.0/). 